\title{
Determination of association between the polymorphism in exon 3 of dopamine receptor gene type 4 with attention deficit-hyperactivity disorder
}

\author{
Hosein Effatpanah ${ }^{\mathrm{a}}$, Mohammad Effatpanah ${ }^{\mathrm{b}}$, Mohammad Javad Mohammadi ${ }^{\mathrm{c}}$, \\ Sahar Geravandi ${ }^{\mathrm{a}}$, Mohsen Ghadami ${ }^{\mathrm{d}}$, Hamidreza Ahmadkhaniha ${ }^{\mathrm{e}}$, Gholamreza Esmaeeli Djavid ${ }^{\mathrm{f}}$, \\ Fariba Arabgol ${ }^{g, *}$
}

${ }^{a}$ Department of Public Health, Asadabad School of Medical Sciences, Asadabad, Iran

${ }^{\mathrm{b}}$ School of Medicine, Ziaeian Hospital, International Campus, Tehran University of Medical Sciences, Tehran, Iran

${ }^{\mathrm{c}}$ Department of Environmental Health Engineering, School of Public Health and Environmental Technologies Research Center, Ahvaz Jundishapur University of Medical

Sciences, Ahvaz, Iran

${ }^{\mathrm{d}}$ Department of Medical Sciences, School of Medicine, Tehran University of Medical Sciences, Tehran, Iran

e Department of Psychiatry, Faculty of Medicine, Iran University of Medical Sciences, Iran

${ }^{\mathrm{f}}$ Department of Microbiology, School of Biology, College of Sciences, University of Tehran, Tehran, Iran

${ }^{\mathrm{g}}$ Department of Psychiatry, Emam Hussein Hospital, Shahid Beheshti University of Medical Sciences, Tehran, Iran

A R T I C L E I N F O

\section{Keywords:}

Attention deficit hyperactivity disorder

Polymorphism

Dopamine receptor gene type

Iran

\begin{abstract}
A B S T R A C T
Introduction: Evidences suggest that attention deficit-hyperactivity disorder (ADHD) is a hereditary disorder and at least 20 potential genes associated with ADHD have been identified. Dopamine receptor gene type 4 (DRD4) has been more considered due to a stronger relationship with ADHD. However, no study has yet been conducted on the Iranian population to assess the association.

Objective: In this study, the association between polymorphism of DRD4 gene with ADHD has been studied among capital of Iran population.

Materials and methods: This study is a case-control study conducted on children aged 6-12 years with ADHD referred to child and adolescent psychiatric clinic Imam Hussein (AS) and normal subjects in 2011. Diagnosis was done based on the DSM-IV-TR criteria and interviewing by two child and adolescent psychiatrists. If parental were consent, then saliva samples of subjects were prepared and DRD4 gene and related allele were evaluated using PCR method. The K-SADS questionnaire was also used to assess comorbid disorders.

Results: In this study, 114 patients in ADHD group and 109 patients in the control group were studied. The most frequency was obtained for allele 4 allele that has been observed in about $90 \%$ of both case and control groups. However, frequency of allele 6 in the case group was $8.8 \%$ where the frequency was $5 \%$ in the control group $(\mathrm{p}=0.02)$. The presence of repeat of allele 6 increased chance of suffering from ADHD to 1.809 (95\% equal to 3.871-0.845).

Conclusion: For the first time this study showed that in Iranian population repeat of DRD4 gene allele 6 unlike the other geographic areas is relatively common and it will increase the chances of suffering from ADHD. However, additional studies are required.
\end{abstract}

\section{Introduction}

Attention deficit and hyperactivity disorder (ADHD) is a syndrome characterized by inattention, distractibility, hyperactivity and restlessness, impulsivity, and other defects in executive function. ${ }^{1}$ The disorder is one of the most common psychiatric disorders with onset in childhood that can infect $5-12 \%$ of children worldwide. ${ }^{2}$ This disorder can create deficiencies in the performance of the individuals and affect all aspects of life. ${ }^{1}$ Frequent job changes, divorce, financial problems in the management of life, increased risk of substance abuse, problems

\footnotetext{
* Corresponding author. Department of psychiatry, Emam Hussein Hospital, Shahid Beheshti University of Medical Sciences, Tehran, Iran. Tel: +982181452361 ; fax: +989122167022 .

E-mail address: farabgol@sbmu.ac.ir (F. Arabgol).
} 
related to driving including high-speed motor vehicle collisions, and side effects such as depression, anxiety, increased risk of anti-social behavior are the main problems cases ADHD symptoms. ${ }^{1,3}$

Genetic and environmental factors are known to be effective in the etiology of this disorder. Twin and adoption studies have mentioned the heritability in the range of $76 \% .{ }^{4}$ Different genes are included in the etiology of this disorder, so that researchers have reported at least 20 types of genes including DAT1, DRD4 and DRD5. ${ }^{2}$ Among the expressed genes Dopamine D4 receptor gene (DRD4) is the most important gene. ${ }^{5}$ This gene is located on chromosome 11 in the region 11P 15,15 and is also the candidate for etiologic psychiatric disorders such as schizophrenia and mood disorders and behavioral traits and behavioral traits such as drug use and diversity.1-4,6

Based on result different genetic and neuropsychological neuroimaging studied, it seems that this gene has a key role in the pathophysiology of ADHD. On the other hand in addition to polymorphisms can make the person prone to this disorder ${ }^{6}$ they can also disturb the response to drugs. ${ }^{3}$ This gene contains 4 exons and some polymorphisms in the encoding area of gene. Most of these polymorphisms occur in exon $\amalg$. These polymorphisms are repeated on a number of variables (VNTR) of 48 base pairs (bp) with repeats 2 to 11 (D4/2 to D4/10). Recent studies have shown that polymorphisms in these genes can be of interference in the appearance of the disorder. However, there is no adequate study in this field.

Various studies have reported that the incidence of repeats in exon III of DRD4 gene in Asian populations is different from other regions. ${ }^{7}$ So far, no study has been conducted in Iran to investigate the prevalence of allele frequency of this gene. This study aimed to evaluate the association of this gene with ADHD inattention, hyperactivity in a group of Iranian population.

\section{Material and methods}

\subsection{Study and samples}

A total number of 223 children aged between 6 and 12 years were chosen for case-control study (one hundred and fourteen cases and 109 controls). Calculation of sample size was performed using a standard error of $5 \%$ or less, $95 \%$ confidence interval and frequency of DRD4 alleles in ADHD. ${ }^{8}$

This cross-sectional study was conducted to in Tehran city, Iran. Cases were chosen from Imam Hossein Hospital, a large hospital located in the center of Tehran from October 2011 to August 2012. Imam Hossein hospital is a tertiary-care hospital with 500 beds, located in the east of Tehran. ${ }^{9}$

Because of location of hospital, referred patients represent a variety of socioeconomic status. Accordingly, the control group consisted of normal children who were chosen during the same study period from kindergarten and schools from all districts of Tehran city. Group matching was based on age and gender. Inclusion criteria were: children (6-12 years old), recorded ADHD diagnosis, and IQ score above 70.

ADHD diagnosis was made using a structured diagnostic interview by two Pediatricians. Cases were diagnosed as ADHD based on the documentation of symptoms that were associated with functional impairment from multiple environments according to the DSM-IV criterion. Children who may have a history of autism, other pervasive developmental disorders and mental retardation which might interact with ADHD diagnosis were excluded. The IQ of all children was assessed with the Wechsler Intelligence Scale for Children-III Thai version (WISC-III). Children with IQ less than 70 were excluded from the study. Also, children who may have a history of autism, other pervasive developmental disorders and mental retardation which might interact with ADHD diagnosis were excluded.

Parents of cases and controls were asked to sign consent forms participate in this study. This project was approved by research Ethics committee of Shahid Beheshti University of Medical Science. All statistical analyses were carried out by the SPSS 13. The collected data were analyzed through chi-square test $\left(\mathrm{x}^{2}\right)$, with a significance level of 0.05. A P-value less than 0.05 was considered statistically significant.

\subsection{Laboratory methods}

In order to DNA extraction, one saliva sample (no less than $30 \mathrm{~min}$ after eating of drinking) was collected from each eligible child. Each sample was collected after mouth washing with water. Then the samples were placed into plastic tubes and were stored at $-20^{\circ} \mathrm{C}$ until analysis.

Genomic DNA was extracted from saliva samples for 114 ADHD subjects and 109 normal controls using PUREGENE ${ }^{\circledR}$ (www.gentra. com). The DRD4 polymorphism was amplified, with forward primer 5'-ACGTCGCGCCAAGCTGCA-3' and reverse primer 5'-TGCGGGTCTGC GGTGGAGTC-3'. Reactions were performed in a 96-well format in a total reaction volume of $25 \mu \mathrm{l}$ containing $2.6 \mu \mathrm{l}$ of $10 \eta \mathrm{g} / \mu \mathrm{l} \mathrm{DNA}, 1 \mu \mathrm{l}$ of each $10 \mu \mathrm{M}$ primer, $2.5 \mu \mathrm{l}$ of PCR buffer, $1.5 \mu \mathrm{l} \mathrm{MgCl}_{2}, 2 \mu \mathrm{l}$ of $10 \mathrm{mM}$ dNTP mix, $0.1 \mu \mathrm{l}$ of Taq polymerase $5 \mathrm{U} / \mu \mathrm{l}$ and $14.3 \mu \mathrm{l}$ of $\mathrm{H}_{2} \mathrm{O}$. PCR was performed using 1 cycle of denaturation for $5 \mathrm{~min}$ at $94^{\circ} \mathrm{C}, 45$ cycles of annealing for $30 \mathrm{~s}$ at $94^{\circ} \mathrm{C}, 30 \mathrm{~s}$ at $65^{\circ} \mathrm{C}$, and $45 \mathrm{~s}$ at $72{ }^{\circ} \mathrm{C}$, followed by 1 cycle of extension for $5 \mathrm{~min}$ at $72^{\circ} \mathrm{C}$. PCR products were run out on a $3 \%$ agarose gel at $100 \mathrm{~V}$ for $100 \mathrm{~min}$.

\section{Results}

In this study, 238 patients participated in two groups including children with attention deficit hyperactivity disorder (ADHD) and control children group that 15 of them were excluded from the study because of lack of appropriate samples and finally 114 subjects in the ADHD group and 109 patients in the control group were studied. Table 1 shows the age distribution of the participants separated by the two groups. As it can be seen, the average age of children in the ADHD group is $9.1 \pm 1.9$ years and in control group $10 \pm 1.2$ years that the observed difference is statistically significant $(\mathrm{p}=0.001)$.

In Table 2, the gender distribution of the participants has been shown separated in two groups. As it was expected, most participants in both ADHD groups were boys (78.9\%). According to the matching of the control group with ADHD group, distribution of boys in these groups is also the same.

In Table 3, the distribution of ADHD subtype in children with this disorder has been identified. Accordingly, the maximum frequency of subgroups can be observed in the subgroups composing from $87.7 \%$ of patients. Subtypes of attention deficit and hyperactivity-impulsivity disorder were in the second and third ratings (Table 3). Additionally, in Table 4 comorbidity of associated disorders in ADHD group has been presented according to which $48.2 \%$ of children have had comorbidity of associated disorders that most frequent case was the confrontational disorders (ODD) that included $43 \%$ of all patients.

DRD4 gene polymorphisms distribution has been presented in Table 5 based on the allele distribution. As it can be observed the most frequency of alleles distribution is observed in the allele 4 that about $90 \%$ was obtained in both case and control groups. However, allele 6 frequency in case group was $8.8 \%$ and the frequency in the control group was $5 \%(\mathrm{p}=0.02)$. The presence of 6 allele repeats increased the chance of suffering from ADHD to 1.809 (95\% equal to 3.871-0.845). Also, DRD4 gene genotype distribution between the two groups in the

Table 1

The age distribution of the study participants into separated groups.

\begin{tabular}{llll}
\hline p-value & Standard deviation & Average age (years) & \\
\hline 0.001 & 1.9 & 9.1 & case group (ADHD) \\
& 1.2 & 10 & Control group \\
\hline
\end{tabular}


Table 2

The gender distribution of the participants separated by the study groups.

\begin{tabular}{llll}
\hline p-value & $\begin{array}{l}\text { Gender } \\
\text { Abundance (\%) }\end{array}$ & \\
\cline { 2 - 4 } & Girl & Boy & \\
\hline 0.846 & $24(21.2 \%)$ & $89(78.8 \%)$ & case group (ADHD) \\
& $22(20.2 \%)$ & $87(79.8 \%)$ & Control group \\
\hline
\end{tabular}

Table 3

Distribution of ADHD subtypes in the case group.

\begin{tabular}{lll}
\hline Frequency percentage & Abundance & \\
\hline $87.7 \%$ & 100 & Combined \\
$7 \%$ & 8 & Inattentive \\
$5.3 \%$ & 6 & Hyperactive-inpulasive \\
\hline
\end{tabular}

Table 4

Distribution of comorbid disorders with ADHD in the case group.

\begin{tabular}{lll}
\hline Frequency percentage & Abundance & \\
\hline $43 \%$ & 49 & (ODD) ppositional-defiant disorder \\
$5.3 \%$ & 6 & Conduct disorder(CD) \\
$51.8 \%$ & 59 & Without comorbidity \\
\hline
\end{tabular}

Table 5

Distribution of DRD4 gene polymorphisms based on the allele types between the two groups.

\begin{tabular}{llll}
\hline p-value & Control group & group ADHD (case) & Alleles \\
\hline \multirow{2}{*}{0.02} & $201(92.2 \%)$ & $205(89.9 \%)$ & 4 \\
& $1(0.5 \%)$ & - & 5 \\
& $11(5 \%)$ & $20(8.8 \%)$ & 6 \\
$3(1.4 \%)$ & - & 7 \\
& $2(0.9 \%)$ & - & 8 \\
& - & $1(0.4 \%)$ & 10 \\
& - & $2(0.9 \%)$ & 11 \\
\hline
\end{tabular}

Table 6

DRD4 gene genotype distribution between the two groups in the case and control groups.

\begin{tabular}{llll}
\hline p-value & Control group & group ADHD (case) & Type of genotype \\
\hline 0.04 & $92(84.4 \%)$ & $92(80.7 \%)$ & 4.4 \\
& $1(0.9 \%)$ & - & 4.5 \\
$11(10.1 \%)$ & $19(16.7 \%)$ & 4.6 \\
$3(2.7 \%)$ & - & 4.7 \\
$2(1.8 \%)$ & - & 4.8 \\
- & $1(0.9 \%)$ & 4.10 \\
& - & $1(0.9 \%)$ & 4.11 \\
& - & $1(0.9 \%)$ & 6.11 \\
\hline
\end{tabular}

case and control groups showed in Table 6.

\section{Discussion}

The obtained evidences from the family information, twins, and adoption to indicate that ADHD is a hereditary and family disorder (91$75 \%) .{ }^{2,4,10}$ At least 20 potential susceptibility genes have been identified in relation to ADHD. ${ }^{4}$ Pharmacological evidences, brain imaging, and animal studies have emphasized the involvement of neurotransmitter systems especially dopaminergic pathway in ADHD. ${ }^{11-13}$ Now half a century has been passed from the beginning of consumption of driving of drugs which have mechanism of action on the dopaminergic system, as the initial treatment in ADHD. ${ }^{10}$ Therefore, the

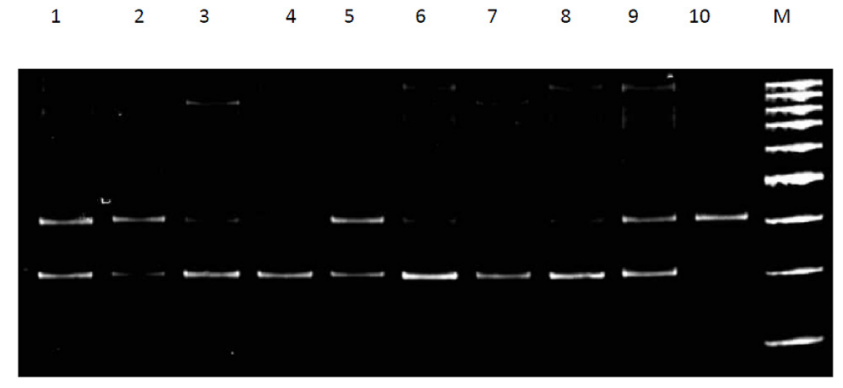

Fig. 1. PCR analysis of the $D R D 4$ repeats polymorphism. Lane 1, 2, 5 and 9: heterozygote with 4 repeats and 6 repeats. Lane 3, 4, 6, 7 and 8, homozygote with 4 repeats. Lane 10: homozygote with 6 repeats.

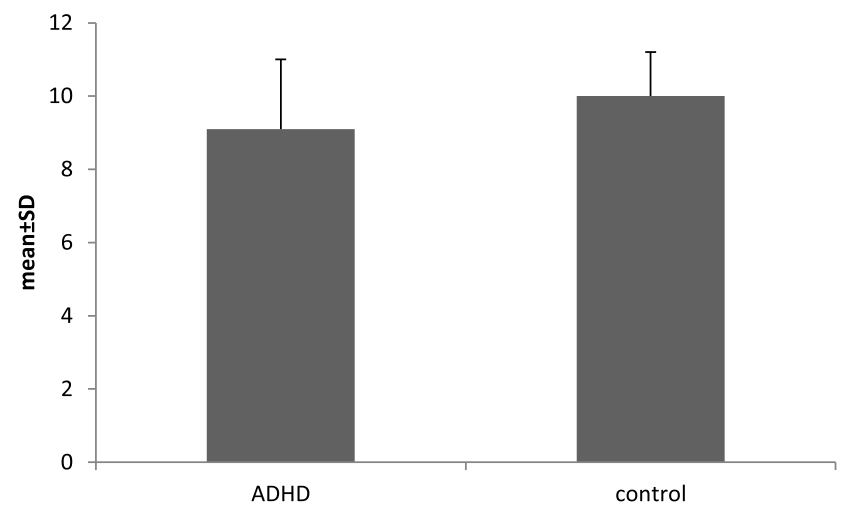

Fig. 2. The age distribution of the study participants separated by the groups.

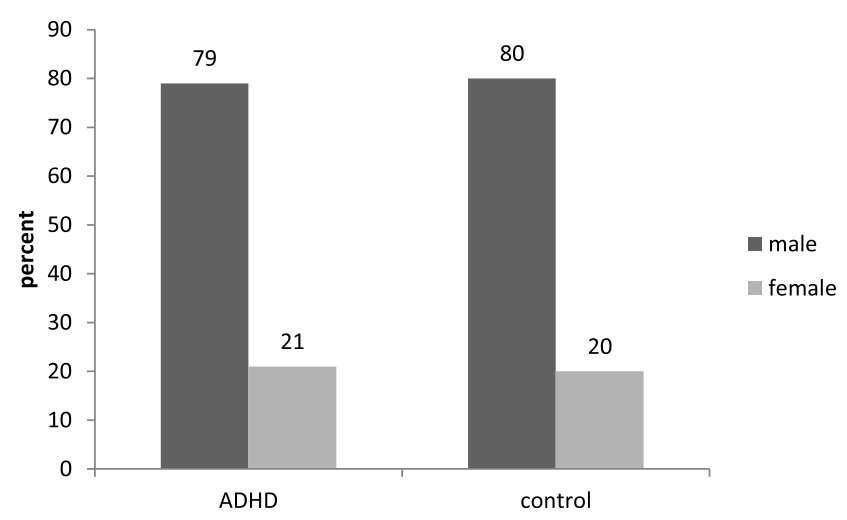

Fig. 3. The gender distribution of the participants to the separate groups studied.

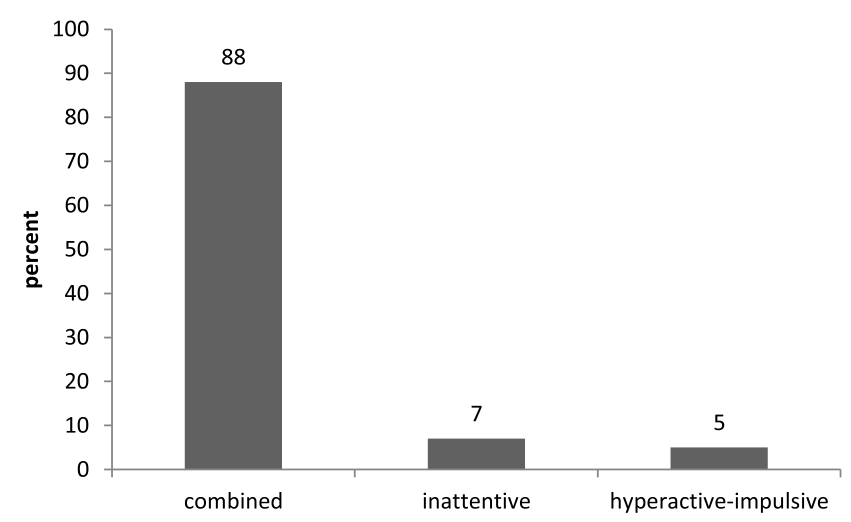

Fig. 4. Distribution of ADHD subtypes in the case group. 


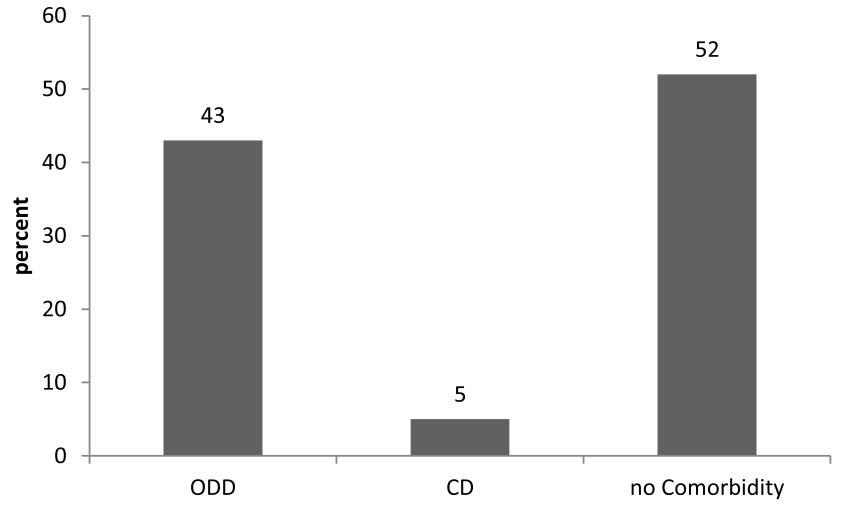

Fig. 5. Distribution of comorbid disorders with ADHD in the case group.

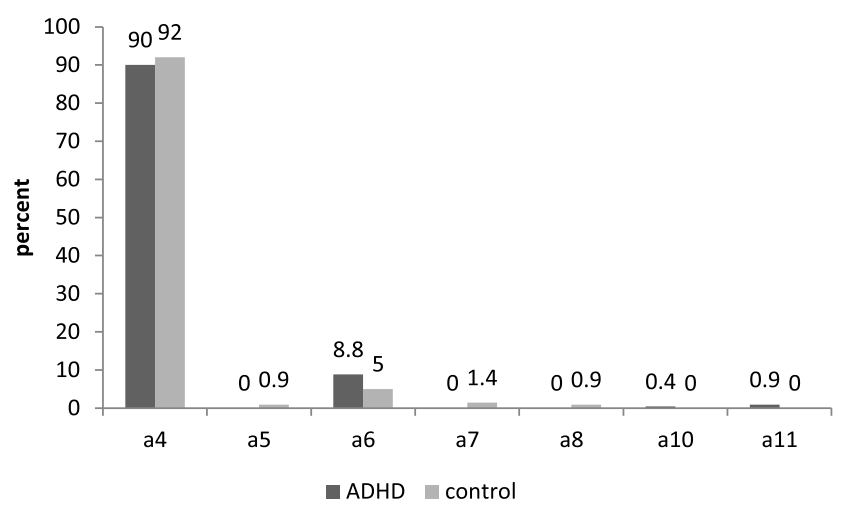

Fig. 6. Distribution of DRD4 gene polymorphisms based on the allele types between the two groups.

transporter and dopamine receptor genes have been more considered than other genes in ADHD disorder. Most genes that have been studied include dopamine transporter gene (DAT1), dopamine receptor gene4 (DRD4), and dopamine receptor gene 5 (DRD5). ${ }^{14}$ Hence the DRD4 gene has been more considered than others associated in ADHD in patients due to its stronger association with this disorder. Based on the metaanalysis which was conducted in 2001 by Faraone, it was shown that among the three genes, most association was obtained in DRD4 and alleles $7 .{ }^{15}$ Accordingly, the presence of repeat 7 allele of the DRD4 gene has increased the likelihood of developing ADHD by as much as 1.45 (95\%, 1.65-1.27) and 1.16 in case-control studies (95\% against 1.31-1.03) that was obtained in family-based studies. According to Li et al. meta-analysis through data collection from 33 studies of pooled odds ratio for ADHD in people who have had repeat allele 7 was 1.34 (with a confidence interval of 1.45-1.23) was calculated. ${ }^{16}$ In other words, a person with ADHD without allele 7 of DRD4 gene is equal to 0.58 . While if the person have a copy of the allele the probability reaches to 0.73 . For those with two have two 7 alleles for DRD4 gene (homozygous) they all are diagnosed with ADHD.

The most frequent allele of DRD4 gene in the general population is allele 4 repeats. ${ }^{10}$ In a study conducted on 1327 people of 36 different nationalities reported that the distribution of alleles in different populations is different. ${ }^{17}$ However, the most frequent allele is associated with allele 4 repeats at $77.47 \%$ (the African) to $43.8 \%$ (in the American population) is different (global average pf DRD4 allele4 repeat is 64.3\%). ${ }^{2,16,17}$ DRD4 alleles distribution has been studied in a few studies in the Middle East. In a study in 2008 in Pakistan which was conducted on 474 volunteers, it was shown that the most common allele in the Persian breed is allele 4 repeat with frequency of $70.1 \%{ }^{18}$ Allele7 repeat in the Persians group was obtained as $8.5 \%$ that was second after allele4. Fig. 1 shows the DRD4 repeat polymorphism.

In this study, allele4 repeat was found as the most frequent allele of
DRD4 gene that was obtained in ADHD and normal groups as $89.9 \%$ and $92.9 \%$ respectively that shows a high frequency compared with global distribution of allele 4repeat of DRD4 gene. Interestingly, in the present study a total of 235 subjects were examined and only 3 people of healthy subjects ( $1.2 \%$ of study participants) demonstrated allele 7 repeat that shows lowest abundance compared with the reported study. Additionally, allele6 that has rarely been reported in various studies was reported in this study, in the group with ADHD with the frequency of $8.8 \%$ and $5 \%$ in healthy subjects. So that in this study it was shown for the first time that the presence of allele 6 increases the probability of suffering from ADHD to 16.809 (95\% equal to 3.871-0.845) (Figs. 2-6).

\section{Conclusions}

Our data confirmed the relationship between polymorphism of DRD4 and ADHD. Further studies with larger population of other groups will be required to explain the relationship between DRD4 polymorphism and the risk of ADHD.

\section{Conflicts of interest}

There are no conflicts of interests among the authors.

\section{Funding/Support}

This work was financially supported by grant: (27) for research Affairs of Hamadan University of Medical Sciences.

\section{Acknowledgments}

Dear Deputy of Research Affairs of Hamadan University of Medical Sciences, Hamadan is grateful for the approval of a funded thesis with the code 27 , as well as the patients and nurses participating in this study.

\section{Appendix A. Supplementary data}

Supplementary data to this article can be found online at https:// doi.org/10.1016/j.cegh.2019.08.016.

\section{References}

1. Martin A, Volkmar FR, Lewis M. Lewis's Child and Adolescent Psychiatry: A Comprehensive Textbook. Lippincott Williams \& Wilkins; 2007.

2. Faraone SV, Sergeant J, Gillberg C, Biederman J. The worldwide prevalence of ADHD: is it an American condition? World Psychiatry. 2003;2:104-113.

3. Sadock BJ, Sadock VA. Kaplan and Sadock's Synopsis of Psychiatry: Behavioral Sciences, clinical Psychiatry. Lippincott Williams \& Wilkins; 2011.

4. Faraone SV, Perlis RH, Doyle AE, et al. Molecular genetics of attention-deficit/hyperactivity disorder. Biol Psychiatry. 2005;57:1313-1323.

5. Ptáček R, Kuželová H, Stefano GB. Dopamine D4 receptor gene DRD4 and its association with psychiatric disorders. Med Sci Monit: Int Med J Exp Clin Res. 2011;17:RA215.

6. Abdolmaleky HM, Smith CL, Zhou J-R, Thiagalingam S. Epigenetic alterations of the dopaminergic system in major psychiatric disorders. Pharmacogenomics in Drug Discovery and Development. vol. 448. Springer; 2008:187-212.

7. Fedi M, Berkovic SF, Macdonell RA, Curatolo JM, Marini C, Reutens DC. Intracortical hyperexcitability in humans with a GABAA receptor mutation. Cerebr Cortex. 2007; 18:664-669.

8. Hosseinpourefeizi M, Noorazar G, Adampourezare M, Golipour Falahi M. Studying association 48 bp polymorphism of DRD4 gene with attention deficit hyperactivity disorder in children from North west of Iran. SSU J. 2017;25:396-403.

9. Hatamabadi H, Alimohammadi H. Reasons for long-stay admission in a typical overcrowded emergency of a teaching hospital in Tehran capital city. Pajoohandeh J. 2008;13:71-75.

10. Sadock BJ, Sadock VA, Ruiz P. Comprehensive Textbook of Psychiatry. Philadelphia: lippincott Williams \& wilkins; 2000

11. Schowalter JE, Biederman J. New developments in pediatric psychopharmacology. $J$ Am Acad Child Adolesc Psychiatry. 1992:31:14-15.

12. Biederamn J, Faraone SV, Mick E, Spencer T. High risk for attention deficit hyperactivity disorder among children of parents with childhood onset of the disorder: a pilot study. Am J Psychiatry. 1995;152:431

13. Faraone SV, Biederman J. What is the prevalence of adult ADHD? Results of a 
population screen of 966 adults. J Atten Disord. 2005;9:384-391.

14. Bakker SC, van der Meulen EM, Oteman N, et al. DAT1, DRD4, and DRD5 polymorphisms are not associated with ADHD in Dutch families. Am J Med Genet Part B: Neuropsychiatric Genetics. 2005;132:50-52.

15. Faraone SV, Doyle AE, Mick E, Biederman J. Meta-analysis of the association between the 7-repeat allele of the dopamine D4 receptor gene and attention deficit hyperactivity disorder. Am J Psychiatry. 2001;158:1052-1057.

16. Li D, Sham PC, Owen MJ, He L. Meta-analysis shows significant association between dopamine system genes and attention deficit hyperactivity disorder (ADHD). Hum Mol Genet. 2006;15:2276-2284.

17. Chang F-M, Kidd JR, Livak KJ, Pakstis AJ, Kidd KK. The world-wide distribution of allele frequencies at the human dopamine D4 receptor locus. Hum Genet. 1996;98:91-101.

18. Mansoor A, Mazhar K, Qamar R. VNTR polymorphism of the DRD4 locus in different Pakistani ethnic groups. Genet Test. 2008;12:299-304. 